\title{
A Case Study of the Design Practices and Judgments of Novice Instructional Designers
}

\author{
Meina Zhu \\ Wayne State University, Detroit, MI, USA \\ ORCID: 0000-0002-5901-9924 \\ Merve Basdogan \\ Indiana University, Bloomington, IN, USA \\ ORCID: 0000-0002-6989-9590 \\ Curtis J. Bonk \\ Indiana University, Bloomington, IN, USA \\ ORCID: 0000-0002-6365-9502
}

Received: 5 Feb 2020

Accepted: 15 Feb 2020

\begin{abstract}
Instructional design and training skills have become a key competency that is expected of public health professionals. However, the research on educating public health students as instructional designers (ID) is lacking. The purpose of this study is to better understand how novice IDs design trainings using their design judgment in an authentic instructional design project in order to provide them with effective educational supports. The data sources of this case study include 11 training lesson plans generated by 37 students through a semester and six semi-structured interviews. The findings reveal that: (1) online games, (2) instructional videos, (3) handouts, (4) PowerPoint presentation slides, and (5) infographics were designed and used by novice IDs. In the midst of the various challenges that were encountered, framing judgment, core judgment, instrumental judgment, navigational judgment, and appearance judgment were manifested in the design process of novice IDs. Based on the findings, practical implementations are recommended to develop effective instructional design curricula for novice public health student designers.
\end{abstract}

Keywords: design judgment, instructional design, instructional design challenges, instructional design practices, novice instructional designers, public health

\section{INTRODUCTION}

Communication skills and strategies are significant for public health professionals to inform and impact diverse individuals, organizations, and communities in an effective and efficient way (Calhoun, McElligott, Weist, \& Raczynski, 2012). Bernhardt (2004, p. 2051) defines the concept of public health communication as "the scientific development, strategic dissemination, and critical evaluation of relevant, accurate, accessible, and understandable health information communicated to and from intended audiences to advance the health of the public."

The above definition of public health communication includes many common features with definitions and descriptions of the instructional design field (Januszewski \& Molenda, 2008; Reiser \& Dempsey, 2018). Reiser (2002), for instance, describes the instructional design as a systematic and reflective process of design, 
development, implementation, management, and evaluation of learning and instruction. Based on this definition, instructional designers' (ID) responsibilities range from the design of training materials such as infographics, job aids, podcasts, flyers, instructional videos, and tutorials; such materials might be employed in the design of online, blended, and conventional courses and workshops. Since one of the main responsibilities of public health professionals is to educate the public, instructional design skills are essential to their success.

Research indicates that expert and novice instructional designers approach the design process differently (Cross, 2004; Kim \& Ryu, 2014). For instance, instructional design experts have the ability to form meaningful problem representations through integrating a variety of information and resource considerations in accordance with their prior knowledge and experience (Ertmer et al., 2008; Rowland, 1992). Such findings indicate that novice instructional designers (ID) are more likely to capture the surface features of the design problem while missing opportunities for integrating and connecting different key issues. In comparison, experts more often can grasp the underlying principles and connections (Ertmer \& Stepich, 2005).

Many government and foundation reports, as well as news stories, increasingly point to the need for professional instructional designers (e.g., Berrett, 2016; Intentional Futures, 2016; Kim, 2018; Richey, Fields, \& Foxon, 2001; Riter, 2016). These reports are a sign that educators need to prepare competent ID professionals in instructional methods through solving real-world problems (Dijkstra, 2005; Jonassen \& Hernandez-Serrano, 2002). However, studies have indicated that simply using problem solving methods to engage learners does not ensure that a novice will automatically transform into an expert (Dufresne, Gerace, Hardiman, \& Mestre, 1992). As Sweller (1988) argued, the traditional means-end method to problem solving, primarily used by novices, is ineffective. To address this issue, Kirschner, Sweller, and Clark (2006) suggested providing scaffolded support and guidance to help novices acquire problem-solving skills.

There are myriad expectations for public health professionals including designing informational and persuasive communications and initiating marketing communication such as health literacy concepts (Calhoun et al., 2012). More specifically, instructional design and training skills have become a key competency that is expected of public health professionals. For instance, a common expectation of community health professionals is educating patients (Community Health Network). Browsing open positions listed at Indeed and Glassdoor, it becomes obvious that the healthcare field needs instructional designers. There are myriad advertisements listed for instructional design consultants, learning and development specialists, learning design managers, process trainers, documentation and training coordinators, digital learning designers, online course writers and designers, hospital education specialists, professional development specialists, active learning instructional designers, and much more. Not surprisingly, the "instructing skill" was listed as one of the key skills for community health workers by MyMajors (https://www.mymajors.com/career/community-health-workers/skills/); a website that helps students create a clear pathway to complete their degree.

Clearly, instructional design courses are now deemed crucial for public health students. Some universities, in fact, provide instructional design courses for public health students such as Chicago Medical School at Rosalind Franklin University and the authors' institution. However, the research on educating public health students as instructional designers is lacking. This case study examines design practices, challenges, and judgments of undergraduate students majoring in public health as novice instructional designers. The purpose is to better understand how they strategically select, plan, develop, implement, and evaluate learning tools and activities using their design judgment in an authentic instructional design project. Hopefully, the results can further inform public health educators of the necessary support structures that can be provided to students to acquire the necessary skills and experiences.

\section{PUBLIC HEALTH SCHOOL STUDENTS AS NOVICE INSTRUCTIONAL DESIGNERS}

The undergraduate public health school students involved in this research study were novice instructional designers who did not have any theoretical and practical experience with the instructional design. 
Previous research has indicated that expert and novice designers approach design processes quite differently (Cross, 2004; Kim \& Ryu, 2014; Rowland, 1992). For example, Cross (2004) observed that novice designers initially identify and explore sub-solutions in-depth, whereas experts, in contrast, constrain their focus to a limited number of initial alternatives.

In addition, Rowland (1992) indicated that experts spent more time on problem analysis. When faced with a design problem or issue, they use their knowledge repertoire to attempt to solve it. However, when information is not available, they attempt to infer it. In this way, they can elaborate on the problem in a richer or more elaborate way than novices who attempt to solve the problem quickly based on surface-related issues or differences. Therefore, novices tend to commit to a solution quickly and then give up when faced with significant challenges.

In a similar fashion, Kim and Ryu (2014) argued that novice designers are less effective at framing a design problem compared to expert designers. For instance, novices tend to change their original design concept when following design steps. Kim and Ryu (2014) proposed that instructional designers could use a design thinking rationality framework, which encourages designers to use higher level (i.e., second-order) semantic connotations and analogical leaps between domains to effectively frame design problems.

Perez, Fleming-Johnson, and Emery (1995) found similar characteristics concerning novice and expert designers. They indicated that experts used more design principles, spent more time understanding the problem domain, and drew solutions from their past experiences. Novices, on the other hand, lacked the knowledge that was important to translate theory into practice. They also adopted a solution too quickly and had difficulty generating more than one possible solution.

Novice and expert designers are sometimes associated with professional and nonprofessional designers (Verstegen, Barnard, \& Pilot, 2008). Professional designers utilize systematic design and development models from prominent sources such as Dick and Carey (2008), Dabbagh and Bannan-Ritland (2004), and Morrison, Ross, Kemp, Kalman, and Kemp (2010). For example, the Dick and Carey (2008) model emphasizes the selection of media and delivery systems while designing and developing lesson materials and strategies. Nonprofessional designers, on the other hand, are subject matter experts (SME), teachers, instructors, or inexperienced designers who specialize in a specific subject area rather than in design. As noted by Saroyan (1992), nonprofessional instructional designers approach the task as a specialist and appear to be directed by their domain knowledge, whereas professionals seem to be directed by instructional design principles.

Given the ill-structured characteristics of the design task, designers have to make initial designs based on incomplete and uncertain information. In addition, they review and modify their decisions when new information is available (Greeno, Korpi, Jackson, \& Michalchik, 1990). In other words, designers are expected to solve design problems that are complex, non-linear, and lack of standard solutions (Verstegen et al., 2008). Such findings also mean that the design process can only be partially planned in advance. Given this situation, designers should be reflective practitioners (Schön, 1983) who constantly review, evaluate, and restructure their practices and take action based on the feedback coming from various sources in the design process.

As noted earlier, experienced instructional designers have a variety of knowledge sources and skills necessary for ill-structured design tasks (Rowland, 1992). Novice designers, on the other hand, seem to lack the required knowledge about possible solutions as well as the flexibility to generate new solutions during the design process. Thus, novices may need more efficient approaches that effectively support them to be able to handle complexities in the design process (Perez et al., 1995).

In order to facilitate novice designers' design processes, teachers can provide guidance and encouragement. According to Keller's (1984) foundational instructional motivation model (ARCS), teachers can facilitate student learning by getting their attention (A), offering relevant (R) examples, providing practice opportunities to enhance their confidence (C) and satisfaction (S). In this research, the researchers implemented a curriculum for novice designers by employing the steps of the ARCS model. In other words, we provided novice designers with theoretical information, technical tools, and examples. Then, our team observed and supported their independent design processes during their lab hours. Our purpose was to 
better understand how we can provide more effective instructional support to novice instructional designers' (ID) in Public Health majors. We investigated their design judgment skills and analyzed how they approached design challenges in the different phases of the design process. The following section discusses the types of design judgments of instructional designers.

\section{INSTRUCTIONAL DESIGN JUDGMENTS}

Educators often provide prescriptive guidance to novice instructional designers through instructional design theories (Reigeluth, Beatty, \& Myers, 2016; Reigeluth \& Carr-Chellman, 1999), principles (Merrill, 2002; Silber, 2007), and models (Branch, 2010) intended to result in effective problem-solving. However, most instructional design theories also emphasize that there is no absolute correct design theory or model for designers. Complicating matters, designers often must make design judgments by themselves (Nelson \& Stolterman, 2012; Smith \& Boling, 2009). These judgments are used in the entire design process (Gray et al., 2015; Nelson \& Stolterman, 2012). Nelson and Stolterman, (2012) argued that judgment does not depend on rules of logic, but, rather, on the accumulation of experiences. They further noted that such judgment is based on one type of knowledge that is related to the specific situation and inseparable from the knower.

Judgment usually deals with a specific situation. For instance, Honebein (2019) mentioned that instructional designers should consider the specific conditions and values to make judgments about useful instructional methods in order to design a learning experience. Conditions refer to objective facts including content, context, and constraints that shape the design. Values, on the other hand, deal with relatively subjective positions of the designer such as goals, priorities, and methods. According to Honebein (2019), instructional designers make judgments about an effective instructional design by considering both conditions and values.

Nelson and Stolterman (2012) identified 12 design judgments. These judgments include the following: (1) framing judgment, (2) default judgment, (3) deliberated off hand judgment, (4) appreciative judgment, (5) appearance judgment, (6) quality judgment, (7) instrumental judgment, (8) navigational judgment, (9) compositional judgment, (10) connective judgment, (11) core judgment, and (12) meditative judgment. These twelve judgments proposed by Nelson and Stolterman (2012) are listed below in the order described in their book.

- Framing judgment is used as an entry point in the design, which defines and embraces the space of potential design outcomes. Designers have to start the design process by setting the stage, by framing the situation, and by moving it toward a satisfactory outcome. Once designers conduct framing judgment, the design process will start.

- Default judgment is an effortless application of high-level skill without conscious deliberation or reflection.

- Off-hand judgment relates to what designers use once they are familiar with a skill, such as driving a car.

- Appreciative judgment refers to what is to be considered as background information and what requires attention as foreground. In other words, the designers use appreciative judgment to decide the priority of their various considerations; such as which aspects should be primarily focused on and require significant attention and which are less important or secondary issues or considerations.

- Appearance judgment is related to stylistic considerations that includes determination of style, nature, character, and experience.

- Quality judgment is a matter of the choice of material such as craftsmanship.

- Instrumental judgments deal with "the choice and mediation of means within the context of prescribed ends" (Nelson \& Stolterman, 2012, p. 152). Anything that can be used as a means to a purpose can be considered as instruments (e.g., videos, technology tools, posters, marker boards, projection equipment, etc.). 
- Navigational judgment is related to making the right choice in a complex and unpredictable situation. Designers should know when to follow the rule book and when not to.

- Compositional judgment puts things together in a relational whole.

- Connective judgment is to create a synthesis of different perspectives, as well as to build a functional assembly from the behaviors of different elements.

- Core judgment is usually buried deep inside us. However, such core judgments seem to be accessible through at least four channels: (1) the individual's character or genius, (2) designer's life experiences, (3) creative experiences, and (4) experiences of the sublime.

- Mediative judgment is used to balance different designer judgments. It is a means of managing and integrating the power of differences using a holistic instrumental approach.

A few scholars have recently provided insights into aspects of a designer's judgment. In a recent study, Boling et al. (2017) explored the core judgment of 11 experienced instructional designers. The study indicated that while designer judgment is rarely discussed in the ID field, these designers do seem to use core judgments in their design. In addition, Lachheb and Boling's (2018) study argued that instrumental judgment plays a critical role in instructional design practice. Accordingly, they suggested that educators develop ID's instrumental judgment. Whereas the above two studies explicated the use of "judgment," other studies have employed other terms to refer to the judgment. For example, Yanchar and Gabbitas (2011) explored the judgment used by instructional designers. They argued that designers used conceptual design sense, which entails a designer's assumptions and values, which need to be explicated through critical reflection.

Despite such inroads into the ID process, scant attention is paid to design judgment in practice (Boling \& Gray, 2014); especially in relation to how novice instructional designers use judgment. Given that the understanding of design judgment can improve designers' design ability (Nelson \& Stolterman, 2012), it is increasingly vital to understand the way that novice instructional designers frame and solve design problems as well as the knowledge that they use. It is also crucial to document and better understand the design strategies that they adopt, the way they manage resources and constraints, and how they monitor and evaluate the design process as a whole. Given that getting to know novice IDs' judgment can help educators obtain strategies to cultivate design judgment, this study is intended to help instructors and instructional designers better understand how instructional design works. A parallel goal is to offer guidance to public health educators when designing courses to improve IDs' skills.

To address the various gaps mentioned above, the current study examines novice IDs' design practices, judgments, and challenges that they encounter when they design training in the Public Health field for an authentic community. The purpose is to understand the design judgments used by novice instructional designers in order to provide better educational support to novice instructional designers from Public Health majors. In line with this purpose, the following research questions guided this study:

1. What learning activities and assessment methods do novice instructional designers design and use?

2. What are the challenges that novice instructional designers encounter when they design and develop various training situations?

3. How is novice instructional designers' judgment manifested in the design process?

\section{METHODS}

\section{Research Design}

In this research, a qualitative case study design was followed in order to empirically analyze persons, events, decisions, and projects within a real-life context (Thomas, 2011; Yin, 1994). Since the purpose of this paper is to investigate the design judgments of novice public health school students in the analysis, design, development, implementation, and evaluation processes of an authentic training development project, a qualitative approach was intended to provide rich insights to interpret their judgments. 
Table 1. Course lesson plan example

\begin{tabular}{lll}
\hline Week Number & Activities & Assignments \\
\hline Week7 & Part 1 & Lab Assignment 4: Design your own logo and \\
& $\begin{array}{l}\text { 1. Recap User Experience Test } \\
\text { 2. Designing a Logo }\end{array}$ & \\
3. Lab Assignment 5: Let's design a logo! & Next Class: Get prepared for the showcase \\
\cline { 2 - 2 } & Part 2 & \\
1. ID Project Workshop & \\
- Analyze the user experience test results & \\
& - Feedback on the evaluation report & \\
\hline
\end{tabular}

\section{Context}

The research context is a three-credit multimedia design course offered to undergraduate students majoring in a School of Public Health at a large Midwestern university in the United States. In this course, students were introduced to the multimedia production process with an emphasis on basic skills and knowledge in instructional design, visual design (prototyping, infographics design, data visualization, Web design, etc.) and audio/video design. Students were expected to collaboratively develop a training that teaches a specific audience either a process or a concept about a public-health topic and an e-portfolio presenting their professional information for potential future employers. The grade distribution of this course included: participation (8\%), laboratory media design and development assignments (40\%), instructional design project (25\%), e-portfolio (20\%), and final presentation (7\%).

The course lasted 16 weeks. The major assignment of the first eight weeks was to design, develop, and deliver a one-hour lesson or training on public health topics. The course content covered the concepts and principles of instructional design and visual design, accompanied by instructional and media design and development practice in a laboratory session (see Table $\mathbf{1}$ ).

Each week, the students were exposed to theory and concepts as well as hands-on applications of that content. The first part of class each week incorporated lectures on theoretical content, such as the concepts, rules, and examples. The second half was a lab session involving hands-on activity time in which students applied what they learned in the first class and worked on their projects independently or in a group. Meanwhile, in assuming a consultative role, the instructors were present for assistance or support if needed.

Once students learned instructional design models and visual design principles, they applied what they learned into design practices such as designing their lessons, brochures, infographics, advertisements, logos, etc. As an example, Figure 1 displays several student works on designing a logo for a health promotion campaign or health- related company. Before this assignment, students were informed about the significance of a logo for a company or an institution. Next, they were shown several popular companies' logos and the stories behind of their designs such as Starbucks, Google, FedX, and Adidas. The intention of this project was to inform students that each visual design should tell us a story and communicate the value of the institution. In the end, students independently designed their logos with or without the facilitation of instructors during the lab sessions. 


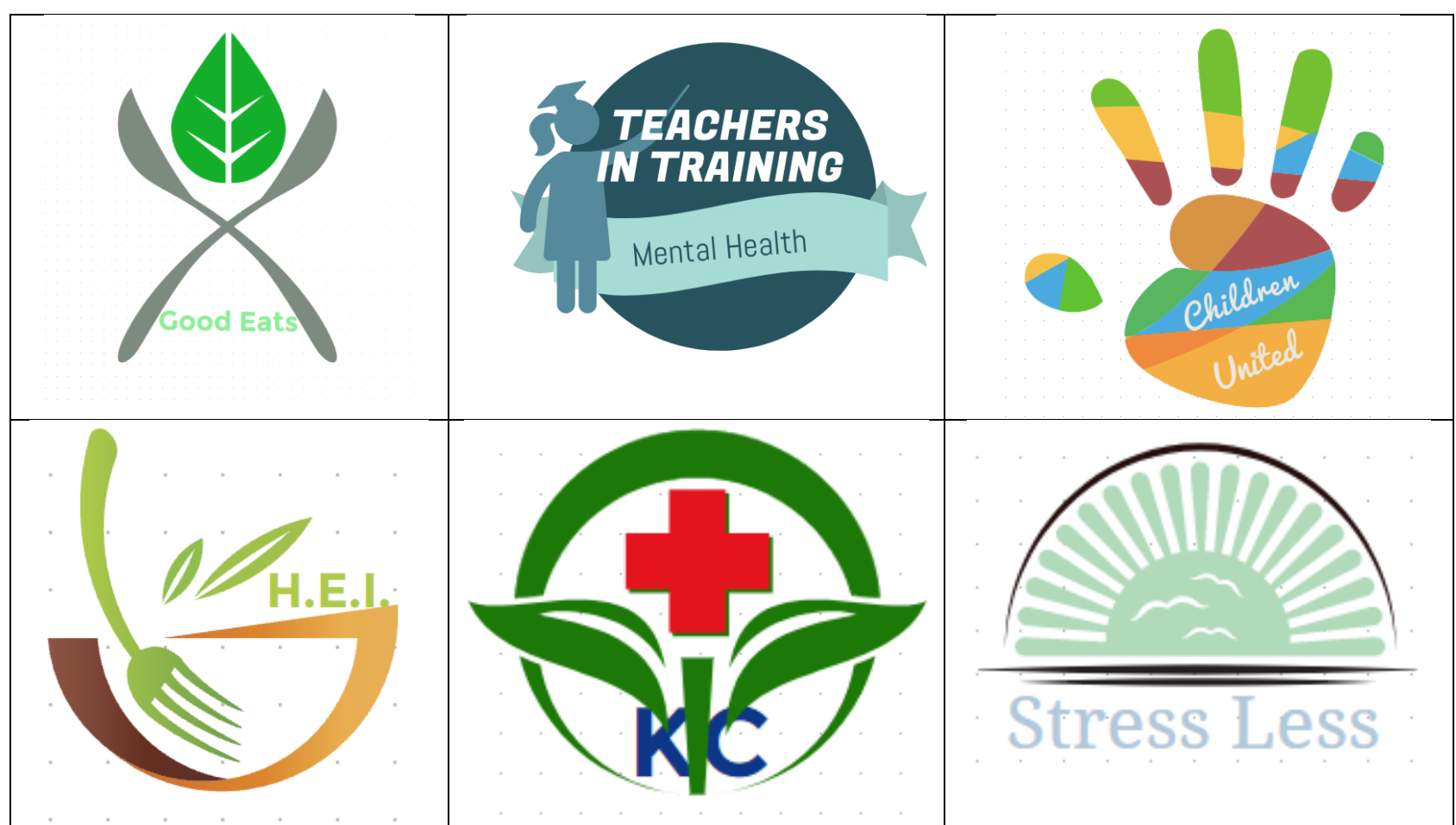

Figure 1. Public health students' design work related to logos

The instructional design procedures used in this course are known as the ADDIE approach which stands for "analysis, design, development, implementation, evaluation" (Branch, 2009, p. 2). The media that they designed could be used in their lesson plan and teaching. Students worked on this capstone assignment for eight weeks in groups of two or three students. The total number of the groups was 11 . Students regularly recorded their analysis, design, development, implementation, and evaluation process into a shared Google document which was accessible to the instructors and the group members. Course instructors provided weekly consultation throughout the project. At the end of the eighth week, the students implemented their training with an authentic audience.

For the second eight weeks, the major assignment was to create an e-portfolio to demonstrate their knowledge and skills. In the meantime, they also kept working on media design and development such as a website evaluation, concept map, instructional video production, podcast production, data visualization, and 3D design and printing. They had the option of placing their production on their e-portfolio website to showcase their learning and production. At the end of the semester, students did a brief five-minute presentation on what they had learned and achieved in this course.

The course had two sections with a total of 37 students enrolled in the Spring of 2018. The two sections were taught by two different instructors from the instructional technology department of the university. To engage students, the course instructors used multimedia and presentation tools such as Nearpod for presentations and Kahoot! for fun quizzes.

\section{Data Collection}

The data collection methods in his study included semi-structured interviews and document analyses for a better understanding of novice instructional designers' judgment when they design training for the community.

\section{Interviews}

Based on an extended literature review, a nine - question interview protocol was designed. Interview questions included their general experiences of designing their lesson plans, specific questions on their design process and design rationale, and the various design challenges that they have encountered. 
We recruited interviewees by disseminating information to students in their face-to-face multimedia design course. Two of the researchers were instructors of that course. After recruiting volunteer students, each researcher interviewed the participants that they recruited. Researchers conducted face-to-face interviews on campus based on participants' preferences. The six interview participants were undergraduate students majoring in community health. Semi-structured interviews lasting 20-30 minutes were conducted with the volunteer students at the end of the semester.

\section{Document analysis}

Eleven lesson plan documents written by 11 teams throughout the semester were analyzed by two of the researchers. Each researcher cross-checked each other's analysis results to achieve consensus.

\section{Data analysis}

Two researchers co-analyzed the interviews and project reports using thematical analysis (Braun, Clarke, \& Rance, 2014) to make valid and replicable inferences from verbal, visual, or written data. The interviews were transcribed through Kaltura and manually checked by the researchers. After transcribing the interview data verbatim (Paulus, Lester, \& Dempster, 2013), we selected one student transcript as a sample, independently read it, and identified codes (the smallest unit of information), categories (the next level of information), and themes. The unit of analysis for this transcript review was the meaning unit. When complete, these researchers continued to analyze the remaining five interview transcripts individually for additional findings. That document analysis followed the same analysis methods.

An expert on design thinking was invited to revalidate the data analysis results to ensure the validity of the analysis. Through an iterative process of individual and collective analysis of the rest of the transcripts and documents, three final themes (e.g., learning activities, design judgment, and challenges) emerged with 17 categories.

\section{FINDINGS}

In an attempt to answer each of the three research questions, the aggregated results of the interview and document analyses are provided below. The goal, of course, is to better understand design practices and judgments of novice public health school students.

\section{RQ1: What Learning Activities and Assessment Methods do Novice Instructional Designers Design and Use?}

The analysis of the interview and lesson plans yielded five categories of learning activities to support the instruction, namely: (1) online games, (2) instructional videos, (3) handouts, (4) PowerPoint presentation slides, and (5) infographics. Each are detailed below.

\section{Online games}

Online interactive games such as Jeopardy games and Kahoot! (see Figure 2) were listed by some groups as engagement tools. One group member stated:

We will create three different games of Jeopardy, that all contain different questions to allow students to work with many other students, as well as answer different questions throughout the interactive game. Jeopardy allows for us to incorporate all of the categories that we cover within our presentation. The categories will include matching foods with their food groups, the daily recommended allotment for foods/food groups, healthy options vs unhealthy options, creating a healthy meal, and healthy food options on campus. Jeopardy will allow the students to have to recite what they have learned without any help, as well as having to retain knowledge from six different categories. 


\section{Sexually}
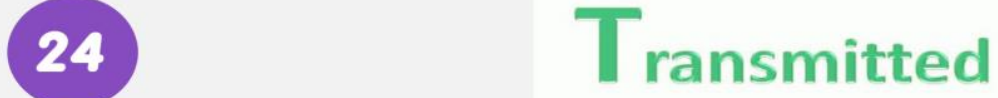

0

Answers

\section{Infections}

Figure 2. Example from Kahoot! game prepared by public health students to test audiences' knowledge on sexually transmitted infections

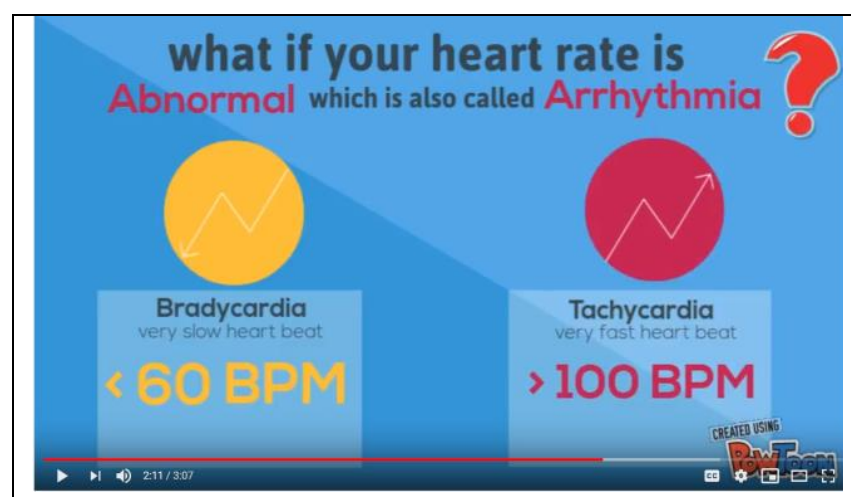

Measuring heart rate

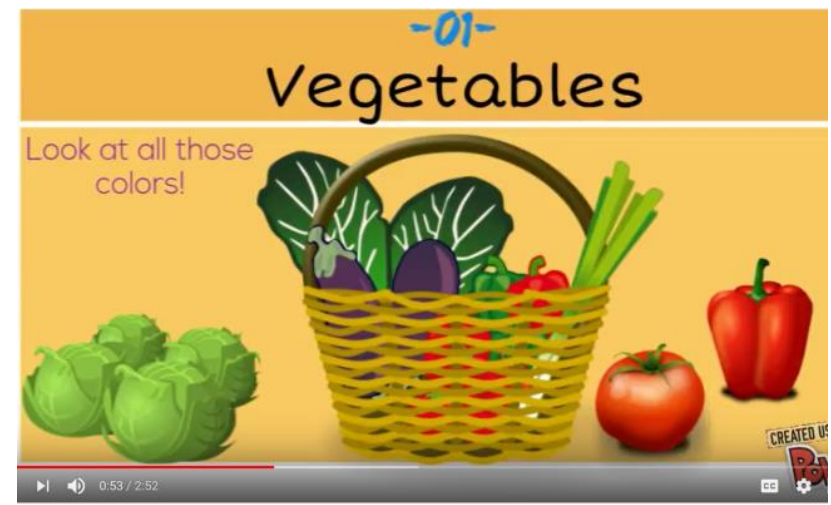

Introduction to nutrition types

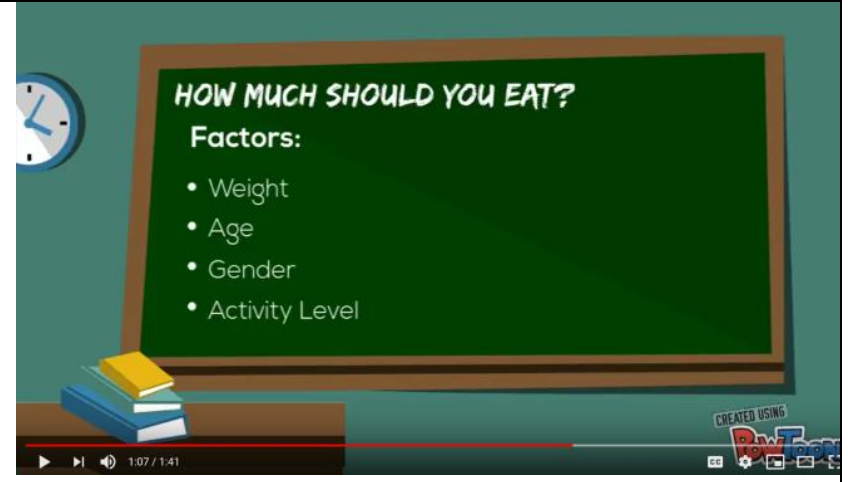

Healthy eating

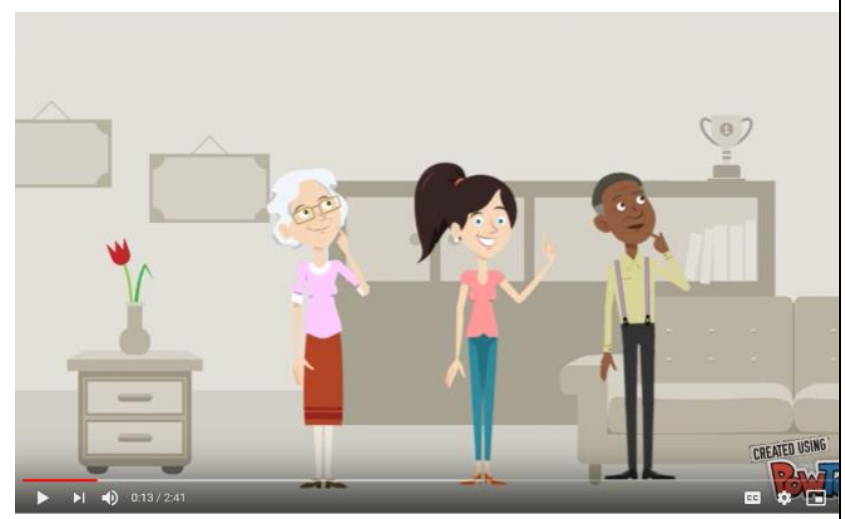

Preventing falls for elderly population

Figure 3. Instructional video examples from public health student course projects

\section{Instructional videos}

Instructional videos are the educational tools that explain key concepts, information, or step by step processes. In this study, students used instructional videos to demonstrate the outcomes of negative behaviors or as an engagement strategy (see Figure 3). For example, a group that focused on sexually transmitted infections (STI) used an instructional video to display knowledge of the dangers of improper 
condom use and unsafe sexual behaviors. In a similar vein, another group used short instructional videos to keep the participants' attention on some in-depth nutrition topics, rather than listening to a speaker for prolonged periods of time. Figure $\mathbf{3}$ presents screenshots from the instructional videos prepared by the students.

\section{Handouts}

Printed materials in the form of handouts to deliver key information in the lecture were preferred by many groups for their efficiency. For instance, one group who designed training material related to how to build healthy meals for busy college students stated that handouts with healthy meal options and substitutions would be provided for easy access during class. That handout would be a reference object during the class as they progressed. In addition, handouts would serve as a type of independent study method for the students. They also stated in their lesson plan document that: "Handouts with recipes, healthy food options, and portion sizes will be given to students to take home so they can pin them up near their refrigerator for quick reference. This will also serve as an independent study method."

\section{PowerPoint presentation slides}

PowerPoint slides were found as one of the most frequently used instructional tools by the students. The group who created training on how to live a healthy life used PowerPoint slides as the main channel of information sharing as indicated in the following excerpt from a project planning document:

The first portion of the PowerPoint will include everything about nutrition. Facts, benefits, and why it is important. The second section of the PowerPoint will include physical activity such as how to fit it into a busy schedule, why it should be done frequently, and [the] benefits for it as well. The last section of the PowerPoint will provide stress management techniques, examples, the importance of it, and how it can improve one's life overall, especially while in college.

\section{Infographics}

Infographics helped designers to communicate information or data in a visually attractive way. Novice IDs utilized this instructional tool to visualize important information and statistics in the instruction. One group felt that "the infographic will help visualize steps for good time management skill." Another group stated that: "We will create an infographic for visualization of common techniques used for managing stress." And a third group noted that: "There may be several infographics displayed throughout the presentation to help our audience better understand the material in a visual way." Clearly, infographics were a tool that was popular for this novice IDs. An example of such an infographic is in Figure 4.

Besides the instructional tools stated above, students also employed different assessment techniques to evaluate the effectiveness of the training. Firstly, self-assessment questions and quizzes were used before, during, and after the instruction. Such a variety of assessment techniques are illustrated in the following quotes.

... To test their knowledge on sexually transmitted diseases and allow each of the students to gather questions on things they are unsure of. This will help us understand what we need to go over in more debt with this group and what we can just quickly recap on.

... We have instant audience feedback. The quiz will give us access to our program participant skill level the moment they submit their quiz answers. This stress-related illness quiz has multiple strengths including, instant results, anonymous data, and we can test to identify what our audience is familiar with versus where they have gaps in knowledge. 


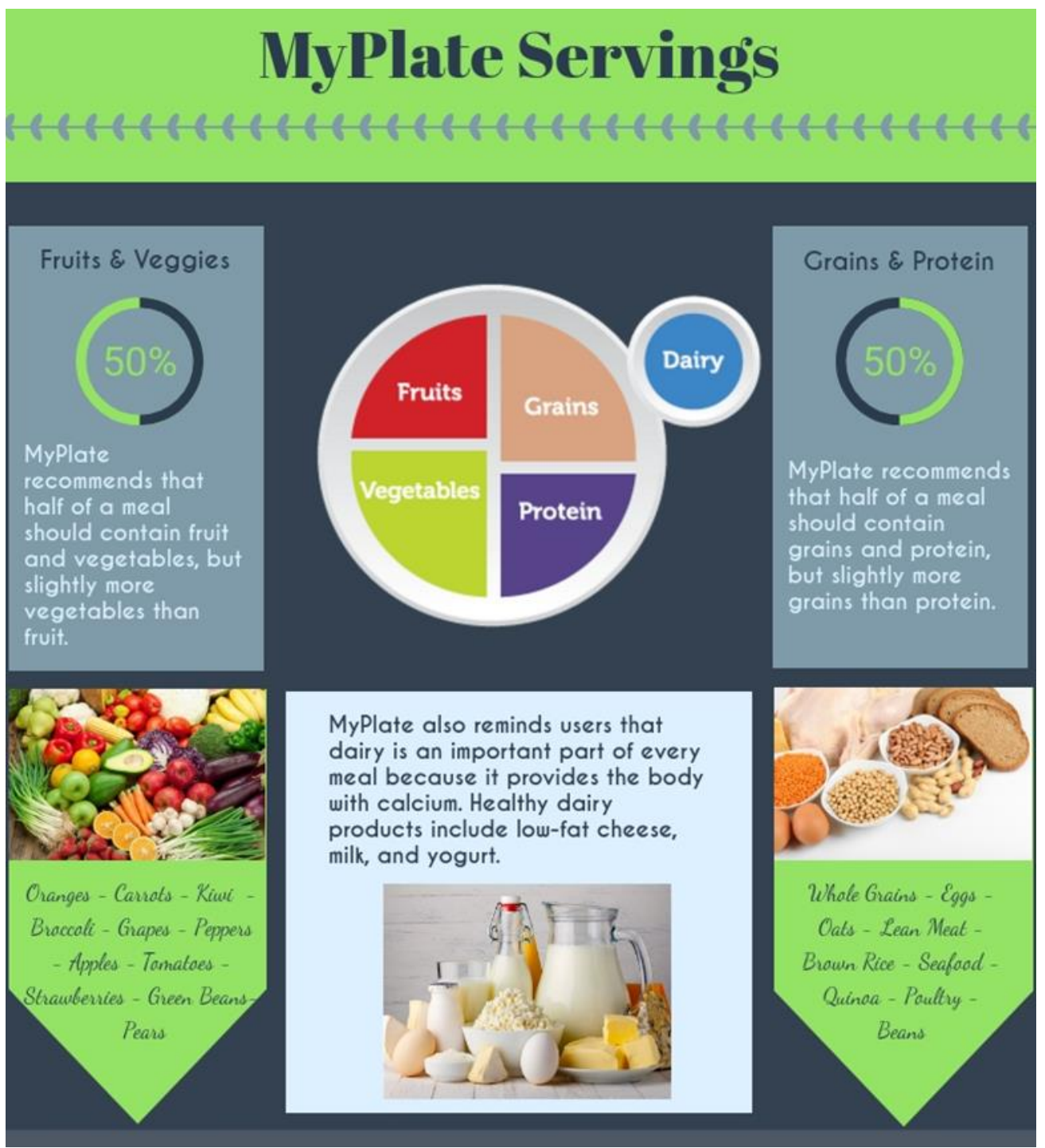

Figure 4. An example of infographic designed by the public health student group members

By giving our audience a quiz, we as instructors are able to receive evidence that our audience was fully engaged in our presentation the entire time and that they receive[d] the information correctly.

The second assessment technique is the use of exit tickets. This technique was stated as a summative test to have a measurable idea of the student's understanding of the material. Per the following quote, one group used emojis as exit tickets.

The ticket will display two questions: question one will be a selection of emojis and they will pick which one they feel best represents their interpretation and understanding of the information; the second question will be asking why they chose that emoji and will also ask them if they learned something, and, if they did, what was it.

Finally, a "Teach Back" technique was found as another assessment techniques employed by several project groups to check the understanding of the students. One group member explained it as follows:

We will implement teach back assessment. This will test the receptiveness of the students but also will get students comfortable in a group setting and they can personally share what resources they are most excit[ed] to implement. This will help grouping the students into similar groups so they can be better matched for better results. 


\section{RQ2: What are the Challenges that Novice Instructional Designers Encounter when they Design and Develop the Training?}

As the instructional design project was provided with a template following the ADDIE approach (Branch, 2009), the challenges that novice instructional designers reported that they encountered were categorized into four phases: (1) analysis phase, (2) design phase, (3) evaluation phase, and (4) implementation phase. A key challenge that students faced in the analysis phase was learner analysis. For example, one interviewee, Kai, stated that:

The learner analysis, this was something... I feel like it was something that kind of a little bit challenging for us, cause I've never done anything like that. For my idea, our target audience was college students here in Bloomington. The question asked [about] the prior knowledge and attitude... It was a little bit challenging, because we have to do a little bit of research. Because it depends on like what country you are. Some countries have different religious backgrounds or ideas towards sexual health. It had to like be very specific in talking about where our audience would be.

During the design phase, the reported challenge was the limited resources. For instance, Emily emphasized that "I think maybe the biggest challenge is that we have very limited resources, and just being three students for a class project. We don't have any money and that kind of thing."

As no challenge was reported in the development phase, in this project, students were required to solicit feedback from both subject matter experts and the target audience before implementation. Challenges reported in this phase included that it is difficult for students to distinguish feedback from different stakeholders such as subject experts and the target audience. Kai, for example, mentioned:

We had the evaluation of the target audience to evaluate the outcomes. So, we understood that. Before that, we had an evaluation process from subject matter expert. Those two together kind of like threw us off. We weren't sure like what we were supposed to write, even though there were questions there.

Last, but not the least, the most frequently mentioned challenges were in [the] implementation phase. The challenges were primarily recruiting audience, technical issues (e.g., loading videos, use projectors, recording problems, etc.), and time management. To provide students authentic learning opportunities in this course, students were required to recruit their audience for their lesson plan delivery. They were stressed with finding enough of an audience given that the lesson was delivered around the mid-term or Week Eight. For instance, Emily stated that "It was more difficult just to find an audience near campus to do it."

Besides recruiting an adequate audience, technical issues were among the primary challenges. For example, Ana reported several technical challenges that her team faced during implementation. As she argued:

I think it was, for us, mostly technical difficulties... Like, I have brought in a camera and a camera didn't have enough memory. And I then brought a second memory for it. At that point I was inside, I couldn't wait to transfer all of that data onto my computer of memory back... That would have made us rather late. And there were students already there and we didn't want to keep them waiting.

In addition, Demi's team faced other technical challenges as she admitted:

We had some technical difficulties like during the first poll, it wasn't unlocked. So they [students] weren't able to respond. But then we had it unlock[ed]. Then, we also had difficulties with the PowerPoint, like the Internet crashed. And so we were to try to get it back. 
As all the novice instructional designers in this course worked in a group with two to three teammates, they encountered challenges during collaboration. The most important issue or challenge related to their time schedule. As Melinda revealed, there were many issues that their team faced:

The only bad thing about it was working with a partner. It is kind of hard [with] different schedules, so it is hard meeting up. I think the hardest part is to find a date that work[s] for everybody. We have like a long time to do it like she gave us a decent amount of time to do it but it was just hard to find.

Overall, a variety of challenges were encountered by students during the analysis, design, evaluation, and implementation phases. However, it seems that novice ID's in the present study rarely reported that they experienced challenges during the development phase.

\section{RQ3: How is Novice Instructional Designers' Judgment Manifested in the Design Process?}

Through qualitative analysis of interview and document data, the design judgments of novice instructional designers were primarily manifested in five different ways; namely, (1) framing judgment, (2) core judgment, (3) instrumental judgment, (4) navigational judgment, and (5) appearance judgment. We detail each of these judgments below.

\section{Framing judgment}

As mentioned earlier, framing judgment is an entry point in the design, which defines and embraces the space of potential design outcomes (Nelson \& Erik, 2012). The novice IDs used framing judgment to better envision the design problems and scope. For instance, in the document, one team mentioned that they framed the scope based on their own values.

The topic we decided to choose is "How to cope with stress and anxiety by using meditation." We decided to select this topic because it is a healthy way to consider in stress management. When people hear the word meditation, they generally think it is something connected to spirituality, but it is actually a way to collect your thoughts.

In terms of selecting their audience for the lesson plan projects, another team considered the needs of the audience by saying that, "This is significant to teach to college freshman because every student faces some sort of challenge with living somewhere new and attempting to adapt to all the changes that come with it."

In accordance with the document data, the interview data also reflect novice instructional designers using framing judgment in their design. For instance, Ana expressed how her team framed the problem in the interview below.

We chose anxiety and college students. And the reason why we chose this is because we are college students ourselves, and we experience it all the time...We could bring in an instructional program that students could truly benefit from, rather than the regular programs that are usually put on campus by different organizations like CAPS.

\section{Core judgment}

Core judgments are usually buried deep inside people (Nelson \& Stolterman, 2012). In this study, diverse core judgments were manifested in novice instructional designers in many ways, including: (1) instruction should be interesting and engaging; (2) instruction should be accessible; and (3) instruction should be effective. First, novice instructional designers held a core judgment that instruction should be interesting and engaging. For instance, Melinda's team stated that:

By using a Prezi rather than a regular presentation, we will be allowed to use audio tools and video tools within the information being presented to create a more creative overall 
presentation that is still organized to help capture the learners' attention more and keep

them interested in the topic.

To engage learners, some novice IDs had the idea that incentives can engage learners. As one team mentioned, "The smoothies will engage our audience because it is an incentive to stay and participate during the instruction."

Another core judgment held by novice IDs is that instruction should be accessible. As one team revealed, "We will make sure to provide them with a small description in order to remind them that the environment is inclusive and open to everyone."

Finally, novice IDs perceived that instructions should be effective for learners. One group noted that "Our reasons for conducting these two assessments are to see if participants actually improved their time management skills, and if our educational training is effective for learners."

\section{Instrumental judgment}

Instrumental judgments in this study connote that the designers deal with choice and mediational means within the context of prescribed ends (Nelson \& Stolterman, 2012). Anything that can be used as a means to a purpose can be considered instruments. It is a broad concept that might cover physical space, multimedia, etc. One team, for instance, revealed their instrumental judgment by identifying the appropriate location for instructional delivery, "There are no students on the McDonalds residence hall floor that would require any accommodations. The room, however, is inclusive and provides easy access for anyone who may need [it] if needed."

Interestingly, most of the instrumental judgments were manifested through multimedia use. For example, one team said, "We provide videos to keep the attention of students while providing information on different techniques for managing and coping with stress." As per the quote below, another team held similar judgments on video use in instruction:

The training will take place face to face, but in addition to the training, there will be a short five minute video to summarize the benefits of meditation. After the video, there will be an interactive demonstration in which students will participate and actually learn meditation skills.

\section{Navigational judgment}

Navigational judgment refers to making the right choice in a complex and unpredictable situation (Nelson \& Stolterman, 2012). Given that novice ID's often face complex and unpredictable situations, navigational judgment is manifested in their design process. One team stated how they altered the learning environment based on the content of the teaching as "Tables and chairs can also be moved around in order to have enough space to practice meditation." Similarly, another team evaluated the prior experience of the audience to make their instructional decisions. As they stated, "A small portion of students have experienced large scale presentations held within auditoriums before. Both small scale presentations as well as larger scale presentations could be effective."

\section{Appearance judgment}

Since this course covers both visual design and instructional design topics, visual design plays a crucial role in the instructional design processes and procedures of novice instructional designers. Appearance judgment refers to the determination of style, nature, character, and experience (Nelson \& Stolterman, 2012). In this study, novice instructional designers integrated visual design principles within instructional design processes. For instance, one team expressed their attention to visual design for instruction by stating, "We used alignment within our PowerPoint to ensure it is clean, organized, and easy to read. We used space within the brochure of our program to help the important designs of it stand out better." Such remarks concur with the previous example, another team manifested their appearance judgment while they chose different colors for 
their instructional materials. As they stated, "we chose colors related to health (green, yellow, and white) that links to some of the same colors included within the pictures for our PowerPoint."

\section{LIMITATIONS OF THE STUDY}

Some limitations exist in this study. First, the study settings were limited to two classes with students majoring in public health. If additional students' design practices and judgments were examined, it might provide a more comprehensive picture of the design processes and judgments of undergraduate public health majors. Second, both interviews and documents were self-reported data, which might not accurately reflect novice instructional designers' practices or perceptions of instructional design. Those intending to address this issue might directly observe the design processes of novice instructional designers. Such observational data can help the researcher with data triangulation. In addition, students enrolled the design course were from different academic levels including freshmen, sophomores, juniors, and seniors. We did not investigate whether student's academic level influences their design judgments.

\section{DISCUSSIONS AND CONCLUSIONS}

This case study examines design practices, challenges, and judgment of novice IDs majoring in the public health field. The purpose of this study is to better understand how novice IDs' design practices and design judgment are used in authentic instructional design projects to provide them with enhanced educational supports. The findings reveal that: (1) online games, (2) instructional videos, (3) handouts, (4) PowerPoint presentation slides, and (5) infographics were designed and used by novice IDs. In the midst of the various challenges that were encountered, framing judgment, core judgment, instrumental judgment, navigational judgment, and appearance judgment were manifested in the design process of novice instructional designers.

Public health students, as novice instructional designers, demonstrated using framing judgment by providing generic rationales for their design problems. The design problems were mostly framed based on public health students' past experiences and core judgments which are usually buried deep inside one's belief system. For example, in the case of the safe sex education, the students framed the issue by stating that sex education is important for college students. However, they failed to provide any depth or extended details regarding why this is the case.

Such results coincide with previous literature that novice instructional designers are more likely to capture the surface features of the design problem while missing opportunities to integrate or connect different issues and pieces of information (Ertmer \& Stepich, 2005). In contrast, experts tend to grasp the underlying principles and connections (Ertmer \& Stepich, 2005; Ertmer et al., 2008; Rowland, 1992). Given these differences, novices attempt to solve the problem quickly based on the surface differences and commit to a solution quickly (Rowland, 1992). Although the subjective position of novice IDs is important, they also need to be taught how to frame the problem based on the objective evidence outside of their own subjectivity. Thus, more practical decision-making models such as SWOT, which refers to strengths, weaknesses, opportunities, and threats (Leigh, 2010), might be helpful to guide novice IDs when addressing instructional design problems and challenges.

Another critical use of designer judgment is core judgment that refers to subconscious limits of value and meaning. In this study, we found that making instruction interesting and engaging, accessible, and effective are some of the core judgments held by the participants. This finding is in line with Boling et al.'s (2017) study which indicated that while designer judgment is rarely discussed in the ID field, designers appear to bring core judgments into their design efforts. In addition, the core judgments identified from the novice instructional designers in the present study also echoed with the perspective of Merrill, Drake, Lacy, and Pratt (1996). Merrill and his colleagues argued that instruction should make "the acquisition of knowledge and skill more efficient, effective, and appealing." (p. 6) Thus, public health educators can leverage students' current design judgment and shape their judgment in the design process if and when the situation arises. 
Third, the selection and design of online games, instructional videos, handouts, PowerPoint Presentation slides, and infographics were found to be outcomes of novice designers using their instrumental judgment. Novice instructional designers selected assorted instruments to meet their different purposes using their judgment. However, the tools and resources that they selected were primarily limited to the instruments presented by the instructors. Therefore, instructors should be cautious about the scope of possible instruments presented to learners. As indicated by Lachheb and Boling (2018), it would be beneficial to teach students how to select the needed tools, resources, and materials, rather than which instruments should be used.

Next, the study found that novice instructional designers demonstrated their appearance judgment using their theoretical visual design knowledge about contrast, color, white space, emphasis, and unity to their training materials. This finding suggests that visual design plays a vital role in instructional design. Thus, instruction on visual elements (e.g., line, shape, volume, color, and texture) and visual design principles (e.g., unity, hierarchy, balance, contrast, scale, and dominance) might enhance their appearance judgment while designing public health training or lessons.

Finally, the novice instructional designers encountered challenges during the analysis, design, evaluation, and implementation phases of the project. Honnebein (2019) discussed these challenges under the name of 'constraints' that refer to the availability of resources such as money, time, and other tools. In particular, many technical issues including poor Internet connections and media demonstration appeared during implementation phases. Some of the novice instructional designers demonstrated their navigational judgment to solve problems. However, most of them failed in these complex situations. As several scholars have indicated, design situations are complex and unpredictable (e.g., Nelson \& Stolterman, 2012; Schön, 1983). Given such complexity, instructional designers should be ready to use their judgment to handle problems and challenges as they arise. Thus, educators might prepare students to be structured and organized, and, at the same time, be flexible and open to uncertainties.

Overall, this study revealed novice IDs' design practices, challenges, and judgments used in their instructional design practices. The findings may inform public health educators of students' experiences and perceptions of instructional design. With a comprehensive understanding of novice IDs' design practices and judgments, educators can better facilitate learners in their learning processes and develop and shape students' design judgments that are related to specific instructional design situations. In other words, academic investigations and discussions on the novice IDs' design conditions (e.g., learner, content, context, and constraints) and values (e.g., goals and framing priorities) would help educators better understand how novice, student IDs make judgments about effective instructional design and help educators better facilitate their students' instructional design processes and decision making.

\section{ACKNOWLEDGEMENTS}

We would like to thank Indiana University Professors Elizabeth Boling and Erik Stolterman who influenced aspects of this manuscript with their consultative advice and design ideas and frameworks.

\section{REFERENCES}

Bernhardt, J. M. (2004). Communication at the core of effective public health. American Journal of Public Health, 94, 2051-2053. https://doi.org/10.2105/AJPH.94.12.2051

Berrett, D. (2016, February 29). Instructional design: Demand grows for a new breed of academic. The Chronicle of Higher Education. Retrieved from http://chronicle.com/article/InstructionalDesign/235425

Boling, E., \& Gray, C. M. (2014). Design: The topic that should not be closed. TechTrends,38 (6), 17-19. Retrieved from https://www.researchgate.net/profile/Colin_Gray3/publication/267451246_Design_ The_topic_that_should_not_be_closed/links/544fcf380cf24e8f7374a821.pdf 
Boling, E., Alangari, H., Hajdu, I. M., Guo, M., Gyabak, K., Khlaif, Z., ... \& Bae, H. (2017). Core judgments of instructional designers in practice. Performance Improvement Quarterly, 30(3), 199-219. https://doi.org/10.1002/piq.21250

Branch, R. M. (2009). Instructional design: The ADDIE approach. New York, NY: Springer. https://doi.org/10.1007/978-0-387-09506-6

Braun, V., Clarke, V., \& Rance, N. (2014) How to use thematic analysis with interview data (process research). In Vossler, A. and Moller, N. P. (Eds.), The counselling and psychotherapy research handbook. London: Sage.

Calhoun, J. G., McElligott, J. E., Weist, E. M., \& Raczynski, J. M. (2012). Core competencies for doctoral education in public health. American Journal of Public Health, 102(1), 22-29. https://doi.org/10.2105/AJPH.2011.300469

Community Health Network. (n.d.). Retrieved from https://www.ecommunity.com/careers/jobs/ community-health-advocate-1903850

Cross, N. (2004). Expertise in design: An overview. Design Studies, 25(5), 427-441. https://doi.org/10.1016/ j.destud.2004.06.002

Dabbagh, N., \& Bannan-Ritland, B. (2004). Online learning: Concepts, strategies, and application. Upper Saddle River, NJ: Pearson Education, Inc.

Dick, W., Carey, L., \& Carey, J. O. (2008). The systematic design of instruction. Columbus, Ohio: Pearson Higher Ed.

Dijkstra, S. (2005). Cognition and instructional design for problem-based learning. In J. M. Spector, C. Ohrazda, A. V. Schaack, \& D. A. Wiley (Eds.), Innovations in instructional technology (pp. 187-206). Mahwah, NJ: Erlbaum.

Dufresne, R. T., Gerace, W. J., Hardiman, P. T., \& Mestre, J. P. (1992). Constraining novices to perform expertlike problem analyses: Effects on schema acquisition. Journal of the Learning Sciences, 2(3), 307-331. https://doi.org/10.1207/s15327809jls0203_3

Ertmer, P. A., \& Stepich, D. A. (2005). Instructional design expertise: How will we know it when we see it? Educational Technology, 45(6), 38-43. Retrieved from http://www.jstor.org/stable/44429251?seq=1\# page_scan_tab_contents

Ertmer, P. A., Stepich, D. A., York, C. S., Stickman, A., Wu, X. L., Zurek, S., \& Goktas, Y. (2008). How instructional design experts use knowledge and experience to solve ill-structured problems. Performance Improvement Quarterly, 21(1), 17-42. https://doi.org/10.1002/piq.20013

Gray, C. M., Dagli, C., Demiral-Uzan, M., Ergulec, F., Tan, V., Altuwaijri, A. A., \& Boling, E. (2015). Judgment and instructional design: How ID practitioners work in practice. Performance Improvement Quarterly, 28(3), 25-49. https://doi.org/10.1002/piq.21198

Greeno, J. G., Korpi, M., Jackson, D., \& Michalchik, V. (1990). Ill-structured problem solving in instructional design. Proceedings of the Annual Conference of the Cognitive Science Society, (pp. 939-946). Hillsdale, NJ: Erlbaum.

Honebein, P. C. (2019). Exploring the galaxy question: The influence of situation and first principles on designers' judgments about useful instructional methods. Educational Technology Research and Development, 67(3), 1-25. https://doi.org/10.1007/s11423-019-09660-9

Intentional Futures (2016, April). Instructional design in higher education. Gates Foundation and Intentional Futures. Retrieved from https://intentionalfutures.com/wp-content/uploads/2017/08/InstructionalDesign-in-Higher-Education-Report.pdf 
Januszewski, A., \& Molenda, M. (2008). Educational technology: A definition with commentary. New York: Lawrence Erlbaum Associates

Jonassen, D. H., \& Hernandez-Serrano, J. (2002). Case-based reasoning and instructional design: Using stories to support problem-solving. Educational Technology Research \& Development, 50(2), 64-77. https://doi.org/10.1007/BF02504994

Keller, J. M. (1984). Use of the ARCS model of motivation in teacher training. In K. E. Shaw (Ed.), Aspects of educational technology: Volume XVII. Staff development and career updating. London: Kogan Page.

Kim, J. (2018, March 8). Career opportunities at the intersection of learning and technology: A talent shortage? Inside Higher Ed. Retrieved from https://www.insidehighered.com/blogs/technology-andlearning/career-opportunities-intersection-learning-and-technology

Kim, J., \& Ryu, H. (2014). A design thinking rationality framework: Framing and solving design problems in early concept generation. Human-Computer Interaction, 29(5-6), 516-553. https://doi.org/10.1080/07370024.2014.896706

Kirschner, P. A., Sweller, J., \& Clark, R. (2006). Why minimal guidance during instruction does not work: An analysis of the failure of constructivist, discovery, problem-based, experiential, and inquiry-based learning. Educational Psychologist, 41(2), 75-86. https://doi.org/10.1207/s15326985ep4102_1

Lachheb, A., \& Boling, E. (2018). Design tools in practice: Instructional designers report which tools they use and why. Journal of Computing in Higher Education, 30(1), 34-54. Retrieved from https://link.springer.com/article/10.1007/s12528-017-9165-x

Leigh, D. (2010). SWOT analysis. In R. Watkins \& D. Leigh (Eds.), Handbook of improving performance in the workplace, vol. 2: Selecting and implementing performance interventions (pp. 115-140). Silver Spring, MD: ISPI. https://doi.org/10.1002/9780470587102.ch5

Merrill, D. (2002). A pebble-in-the-pond model for instructional design. Performance Improvement, 41(7), 4146. https://doi.org/10.1002/pfi.4140410709

Merrill, M. D., Drake, L., Lacy, M.J., Pratt, J. (1996). Reclaiming instructional design. Educational Technology, 36(5), 5-7. Retrieved from http://mdavidmerrill.com/Papers/Reclaiming.PDF

Morrison, G. R., Ross, S. M., Kemp, J. E., \& Kalman, H. (2010). Designing effective instruction. New York, NY: John Wiley \& Sons.

Nelson, H. G., \& Stolterman, E. (2012). The design way: Intentional change in an unpredictable world (2nd ed.). Cambridge, MA; London, UK: MIT Press. https://doi.org/10.7551/mitpress/9188.001.0001

Paulus, T., Lester, J., \& Dempster, P. (2013). Digital tools for qualitative research. Thousand Oaks, CA: Sage. https://doi.org/10.4135/9781473957671

Perez, R. S., Johnson, J. F., \& Emery, C. D. (1995). Instructional design expertise: A cognitive model of design. Instructional Science, 23(5-6), 321-349. https://doi.org/10.1007/BF00896877

Reigeluth, C. M., Beatty, B., \& Myers, R. (2016). Instructional-design theories and models, Vol. IV: The learnercentered paradigm of education. New York, NY: Routledge. https://doi.org/10.4324/9781315795478

Reigeluth, C. M., \& Carr-Chellman, A. (1999). Instructional-design theories and models (Vol. II): A new paradigm of instructional theory. New York, NY: Lawrence Erlbaum.

Reiser, R. A. (2002). A history of instructional design and technology. In R. A. Reiser, and J.V. Dempsey (Eds.), Trends and issues in instructional design and technology (pp. 26-53). Upper Saddle River, NJ: Merrill Prentice Hall. 
Reiser, R. A., \& Dempsey, J. V. (Eds.) (2018). Trends and issues in instructional design and technology (4th ed.). Boston, MA: Pearson Education, Inc.

Richey, R., Fields, D. C., \& Foxon, M. (2001). Instructional design competencies: The standards. Syracuse, NY: ERIC Clearinghouse on Information \& Technology.

Riter, P. (2016, June 7). The quest for great instructional designers. Inside Higher Ed. Retrieved from https://www.insidehighered.com/advice/2016/06/07/troublesome-shortage-instructional-designersessay

Rowland, G. (1992). What do instructional designers actually do? An initial investigation of expert practice. Performance Improvement Quarterly, 5(2), 65-86. https://doi.org/10.1111/j.19378327.1992.tb00546.x

Saroyan, A. (1992). Differences in expert practice: A case from formative evaluation. Instructional Science, 21(6), 451-472. https://doi.org/10.1007/BF00118558

Schön, D. A. (1983). The reflective practitioner: How professionals think in action. New York, NY: Routledge.

Silber, K. H. (2007). A principle-based model of instructional design: A new way of thinking about and teaching ID. Educational Technology, 47(5) 5-19. Retrieved from https://www.jstor.org/stable/44429438?seq=1\#metadata_info_tab_contents

Smith, K. M., \& Boling, E. (2009). What do we make of design? Design as a concept in educational technology. Educational Technology, 49(4), 3-17. Retrieved from https://eric.ed.gov/?id=EJ865542

Sweller, J. (1988). Cognitive load during problem solving: Effects on learning. Cognitive Science, 12, 257-285. https://doi.org/10.1207/s15516709cog1202_4

Thomas, G (2011). How to do your case study: A guide for students and researchers. London: Sage.

Verstegen, D., Barnard, Y., \& Pilot, A. (2008). Instructional design by novice designers: Two empirical studies. Journal of Interactive Learning Research, 19(2), 351-383. Retrieved from https://www.learntechlib.org/p/22961/

Yanchar, S. C., \& Gabbitas, B. W. (2011). Between eclecticism and orthodoxy in instructional design. Educational Technology Research and Development, 59(3), 383-398. https://doi.org/10.1007/s11423010-9180-3

Yin, R. K. (1994). Case study research: Design and methods (2nd edition). Thousand Oaks, CA: Sage.

Correspondence: Meina Zhu, Learning Design and Technology program, College Education at Wayne State University, 365 Education Bldg., Detroit, MI 48202, USA. E-mail: meinazhu@wayne.edu 